The practice of quoting the titles of foreign papers is aggravating in the extreme, especially when accompanied by the remark that " this laborious but lengthy paper is not suited for " 2 bstraction!"”

I seldom go out of our foggy little island without hearing our want of familiarity with what is going on elsewhere roundly and deservedly abused. But I feel bound to say that, more especially in France, $I$ can justly retaliate.

Russian science is said to be very productive. That language, at all events, is beyond most of us.

New University Club

Marshaly. Hall

\section{Aurora Australis}

OBSERVING in NATURE of Oct. 27 , an account of a brilliant aurora observed in England on the 23rd to the 25th of that month, I think it may excite attention to the subject by informing your readers that at the same date a splendid display of Aurora Australis was recorded at most of the meteorological stations in this colony.

The extent of sky covered was not so great as in the fine display on 5th April last, which was also coincident with a renarkable Aurora Borealis, but the red tint was so much deeper than usual, that many persons in this place attributed the phenomenon to the glare of the great fire which destroyed the town of Lyttelton, and the news of which was just then received by telegraph.

JAMES HECTOR

Colonial Museum and Observatory, Wellington, N.'Z., Jan. 2

\section{Ocean Currents}

$\mathrm{Mr}$ rejection of the idea that permanent differences of atmospheric pressure could produce any effect on Ocean Currents, was meant to be as sweeping as Mr. Johnston considers it. I believe that the idea is repugnant to the most elementary conceptions of hydrostatic equilibrium; and I am particular in so far repeating the gist of my former letters, becalise Mr. Johnston, in his letter in NATURE for March 9, reiterates his suggestion that difference of atmospheric pressure is a power in the production of Ocean Streams, and whether he suggests that it is a supplementary power, or a chief one, is nothing to the purpose, if, as $Y$ distinctly maintain, it is not a power at all.

My rejection of the idea that the formation of these differences of pressure can produce any appreciable effect, is quite as decided; but $\mathrm{Mr}$. Johnston is mistaken when he speaks of my denying also the influence of the movement of these differences of pressure; for my remarks concerning them were to the very opposite purport; and I pointed out that such movements do sometimes give rise to rapid and dangerous sets, known as storm-currents, which in their irregular and exceptional nature, differ essentially from those regular permanent or periodic currents usually understood by the general term Ocean Currents, though they may occasionally modify them both in direction and velocity.

I would also call Mr. Johnston's attention to the fourth paragraph of his letter, and assure him that I have never, directly or indirectly, maintained that the Trade Winds "would account for the whole of the phenomena of Ocean Currents;" but I have maintained, and do still maintain, that all the phenomena alluded to may be very satisfactorily accounted for by a reference to the prevailing winds of the different parts of the world; and that the Gibraltar Current is to be attributed, not to the local, partial, and peculiar wind of the Straits, but to the great body of the west wind of the North Atlantic, which also produces a northerly current on the coast of France, known distinctively as Rennell's Current, and a southerly current on the coast of Portugal.

$I$ have discussed this question so fully in another place, that $I$ should be only repeating myself were I to say more about it here ; but I may add that though, as Mr. Johnston asserts, undercurrents cannot be caused primarily by the action of the winds, they can be, and frequently are, caused secondarily by that action ; and many a ship has owed her safety from the apparently imminent danger of a lee-shore, to the "under-tow," or reflux of the water swept towards the shore on the surface. If there is a deep-flowing outward current in the Straits of Gibraltar, I believe it to be exactly of the nature of an "under-tow ;" it seems to me probable enough that there is occasionally such an outward current; but I cannot admit that the one observation of it which Dr. Carpenter considers he obtained, after several attempts made in vain, has abundantly proved its existence; still less can I admit that it is necessary to call in difference of temperature and density to account for it.

$\mathrm{Mr}$. Croll considers that there is a similar escape of water, underneath, from the northern to the southern hemisphere, and his arguments appear to warrant the suggestion, although no such under-current, or system of under-currents, has yet been observed. I see no improbability in the idea; but so many mistakes have, at different times, been made by trusting rather to theory than to positive evidence of fact, that we cannot be too cautions in admitting the existence of such under-currents, without any reliable observations. For that recorded by Captain Maury, to which Mr. Johnston refers, has, from the vague manner in which it is describsed, no scientific value whatever. There is no mention of locality, season, direction of wind, swell or surface current, no mention of the relation between the effect ive area of the "block of wood loaded to sinking" and the barrega or breaker which floated it; the depth is spoken of as indifferently one hundred or five hundred fathoms ; above all, no mention is made of any means being taken to distinguish between an apparent and real set of the breaker. It is quite clear that if the loaded block was lowered into still water, the breaker to which it was attached was, to a certain extent, moored, and the surface drift of the boat away from it would give it all the appearance of moving in the opposite direction. No mention is made of the method adopted to discriminate; or, in fact, of any method at all being adopted, or any attempt made to eliminate or neutralise the many errors which necessarily find their way into such an observation; all that we are told is that "it really appeared as if some monster of the deep had laid hold of the weight below, and was walking off with it." To such an account one is almost attempted to add-very like a whale.

I have dwelt on the thoroughly unsatisfactory nature of this experiment, because, from the description of it having been repeated in every edition of the "Physical Geography of the Sea," I find it constantly referred to-as Mr. Johnstun has now referred to it -as a conclusive proof of the existence of strong counter under-currents at great depths; where as in reality it is a proof of nothing, unless, perhaps, of the careless style of observing which was accepted as sufficient twenty years ago.

The other instance which Mr. Johnston brings forward would be really remarkable, if we only had some evidence of it as a fact; he speaks of the warm water of the Atlantic dipping down beneath the cold and "specifically lighter" water of the east Greenland current. It has been well known, long before the late Gernan expedition, that at the meeting of the two waters there is a distinct line of demarcation, but such a line does not necessarily indicate a dip of either water, such as Mr. Johnston describes; as indeed has been very fully shown by the survey of the nearly vertical "cold wall" of the United States, along which the line of demarcation is more distinct than anywhere in the world. And besides, can we admit that the water of the East Greenland current is "specifically lighter" than that from the Atlantic? that the cold water is lighter than the hot, the salinity of the two being very nearly equal? Captain Maury speaks of hot water, like oil, running over cold ; Dr. Carpenter illustrates the same idea in a long glass trough, showing plainly enough the way in which he conceives the interchange to take place. I do not attach so much value as Dr. Carpenter does to this illustration, which represents a system of motion entirely different from that of the ocean-currents; but accepting it as the exposition of the views held by the leading supporters of the claims of temperature and density, it is utterly antagonistic to the idea of this extraordinary dip of warm water said to take place near the east coast of Greenland. Whether we consider it from a purely theoretical or from a geographical point of view, the idea is wholly unsupported, and can only be classed as one of those crude speculations which, in every branch of science, do so much harm by tending to unsettle the minds of those who indeed take an interest in the subject, but have not made it a special study.

J. K. LAUGHTON

\section{Draper's Experiment simplified}

Wishing to repeat Draper's Experiment, and casting about for a simple method of performing it, it occurred to me to take advantage of the intense heat evolved in the combustion of sodium, and, beginning with the entire spectrum, watch its degradation as the heat declined; to which end I formed a shallow, conical cup of thin copper wire, half an inch in diameter, and, putting therein a piece of sodium, applied a spirit-lamp till 